\title{
Factors and Conditions of Functioning and Development of Modern Regional Socio-Economic Systems
}

\author{
Submitted 10/01/19, $1^{\text {st }}$ revision 20/03/19, $2^{\text {nd }}$ revision 08/05/19, accepted 03/06/19
}

\author{
I.V. Zimakova ${ }^{1}$, A.N. Kalashnikov ${ }^{2}$, S.I. Kretsu ${ }^{3}$, A.V. Kurillo ${ }^{4}$ \\ Abstract:
}

Purpose: The purpose of this article is the systemic modernization of scientific ideas relating to the essential factors and conditions of functioning and development of regional socioeconomic systems.

Design/Methodology/Approach: To substantiate the article about the possibility of overcoming the socio-economic stagnation and recession of the region's economy based on modernization of research tools and management of local and regional socio-economic processes using modern agglomerative technologies and methods.

Findings: Finding lies in clarifying the arrangement, structure and importance of socioeconomic processes, factors and conditions of local, regional and interregional level that determine the effectiveness and sustainability of functioning of the economy.

Practical Implications: Are determined by the possibility to use authors' scientific results for audit, evaluation and adjustment of regional socio-economic impacts, measures and development programs, used during designing, forecast and assessment of socio-economic and complex efficiency of local and regional socio-economic activeness in the cities and municipal areas.

Originality / Value: It is substantiated by development of the theory and methodology of regional studies of socio-economic factors and conditions that determine long-term prospects of stable functioning and sustainable development of the regional economy on the basis of adaptation of the basic direction of the system and reproduction processes.

Keywords: Regional economy, regional socio-economic system, regional economic processes.

JEL Code: D30, D39.

Paper Type: Research article in Special Issue dedicated to Russian Economy.

Section 7: Economic Development.

\footnotetext{
${ }^{1}$ Post-graduate of the Department of Economic Security, Kuban State Technological University,zimakova@mail.ru

${ }^{2}$ Post-graduate of the Department of Economics and Modelling of Industrial Processing,

Belgorod National Research University, kalashnikov@mail.ru

${ }^{3}$ Post-graduate of the Department of Economic Security, Kuban State Technological

University, krechu@mail.ru

${ }^{4}$ Post-graduate of the Department of Economic Security, Kuban State Technological

University,kurillo@mail.ru
} 


\section{Introduction}

Socio-economic systems of modern Russian regions have the significant potential in accelerating territorial economic development, but require to be more qualitatively focused than before, on investigation both factors and conditions that determine their formation and functioning in the context of strategic priorities of sustainability and balance, competitiveness and social orientation and responsibility in relation to the population and labour resources of local and regional structures and entities. Prospective economic development within the region, country, global economic space is impossible without innovative approaches to understanding nature of socioeconomic processes at local and regional levels, their synchronization and system coordination by methods of the regional economy strategic management (Bondarenko, 2007; Tinyakova and Ratushnaya, 2010; Volkova and Tinyakova, 2013).

\section{The Proposed Approach to the Study of Factors and Conditions of Functioning and Developing Regional Socio-economic Systems (RSES)}

The modern level of the theory of the regional economy relating to substantiation necessity to identify and investigate regional socio-economic systems is associated with the search for and classification of the constituents of the RSES, choice of control actions corresponding to the current and future state of the participants of the RSES, the implementation of control impact in accordance to further assessment of the effectiveness / efficiency of used methods. As a conclusion to the implemented investigation of theoretical and methodological concepts and approaches relating to the development and management of regional socio-economic systems, it must be admitted that in the absence of an adequate theoretical and methodological basis for determining functionality of such systems and ormalization of their subject-object structure and subject interactions, existing scientific investigation in this problem area is limited to nomination and axiomatic substantiation of general scientific hypotheses, which do not have applied confirmation and economic significance (Molchan, 2011; Molchan, 2013). The author's scientific search relating to factors and conditions of functioning and developing the regional socio-economic system of modern regions allowed to obtain new scientific results in the following key areas:

- determination and understanding of local socio-economic process nature as a sequence of stages in the formation, the use and reproduction of the labour potential of the territory;

- consideration of the local socio-economic system as a structure mediating local socio-economic processes;

- the study of nature and features of the regional socio-economic process as a set of local socio-economic processes and process of redistribution of the labour resources in the region; 
- visualization of the structure and determination of functionality of the regional socio-economic system, which can provide system and uninterrupted regional socioeconomic development;

- the development of classification features and substantive differences of the regional economic system and regional socio-economic subsystem.

The author's conception of local socio-economic process, considering its main subjects, content and features, is represented in Figure 1. Despite there are public authorities and economic management systems within a certain location, in principle local socio-economic process can be implemented in two forms: in the centralized form and in the decentralized one, as well as in a mixed form (which seems to be the most effective, since it allows to combine both forms of process, taking into account specific purposes of sectoral and regional / local economic and social development). Local socio-economic system as a mediator of local socio-economic processes should provide following managerial capabilities:

Figure 1. Local socio-economic process: subjects, content and features (author's conception)

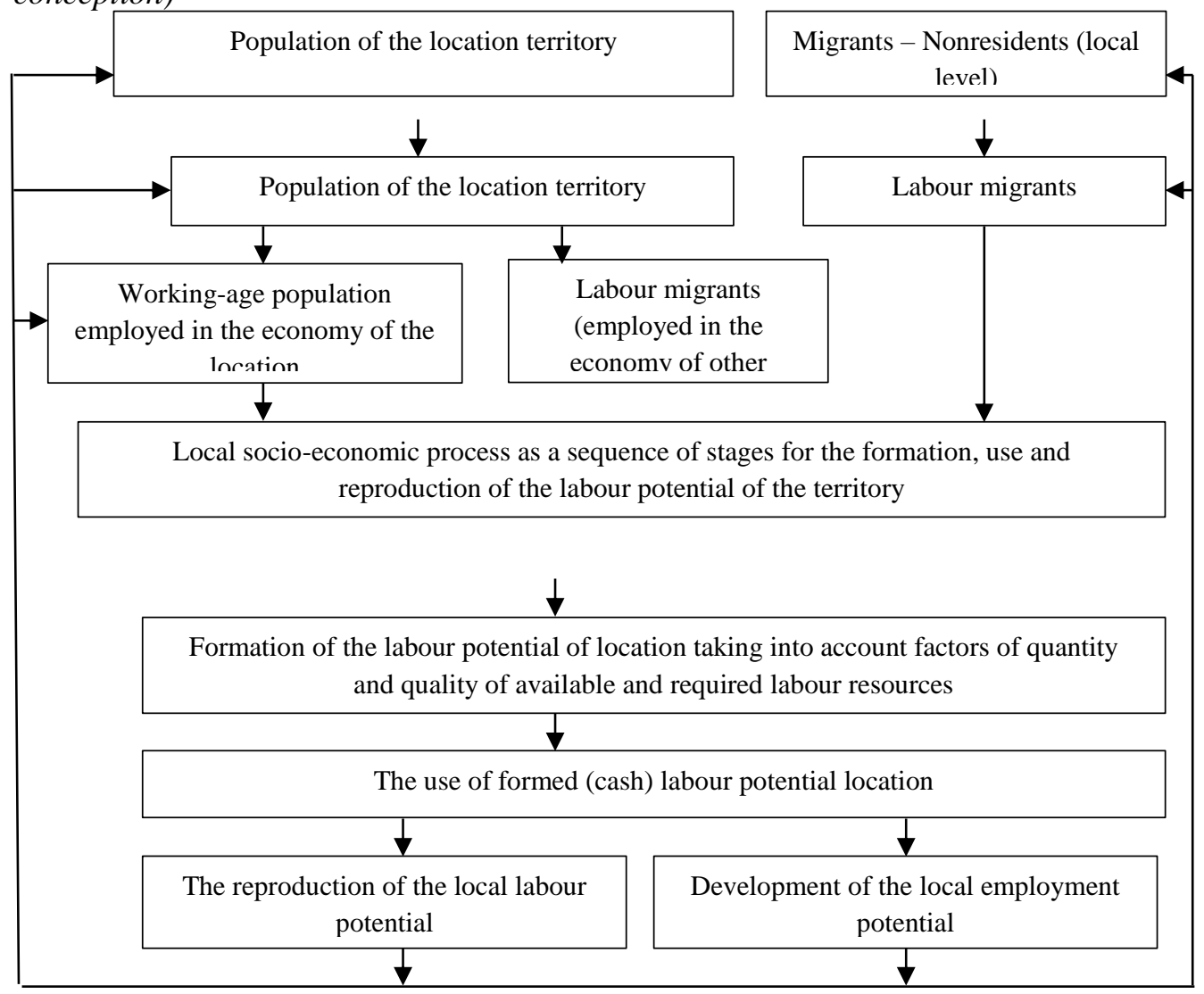


- formation of institutional infrastructure in institutions of management of labour migrants' resources and institutions focused on the endogenous labour potential;

- formation of policy relating to regulation of proportion between internal and external labour resources as a factor in supporting local economic growth, considering the point approach;

- monitoring, control and correction of basic indicators of availability, use, reproduction and development of the labor potential of the territory.

Condtituents and structure of the local socio-economic system as a mediator of local socio-economic processes, are described in the author's interpretation in Figure 2.

Figure 2. Local socio-economic system as a mediator of local socio-economic processes (author's conception)

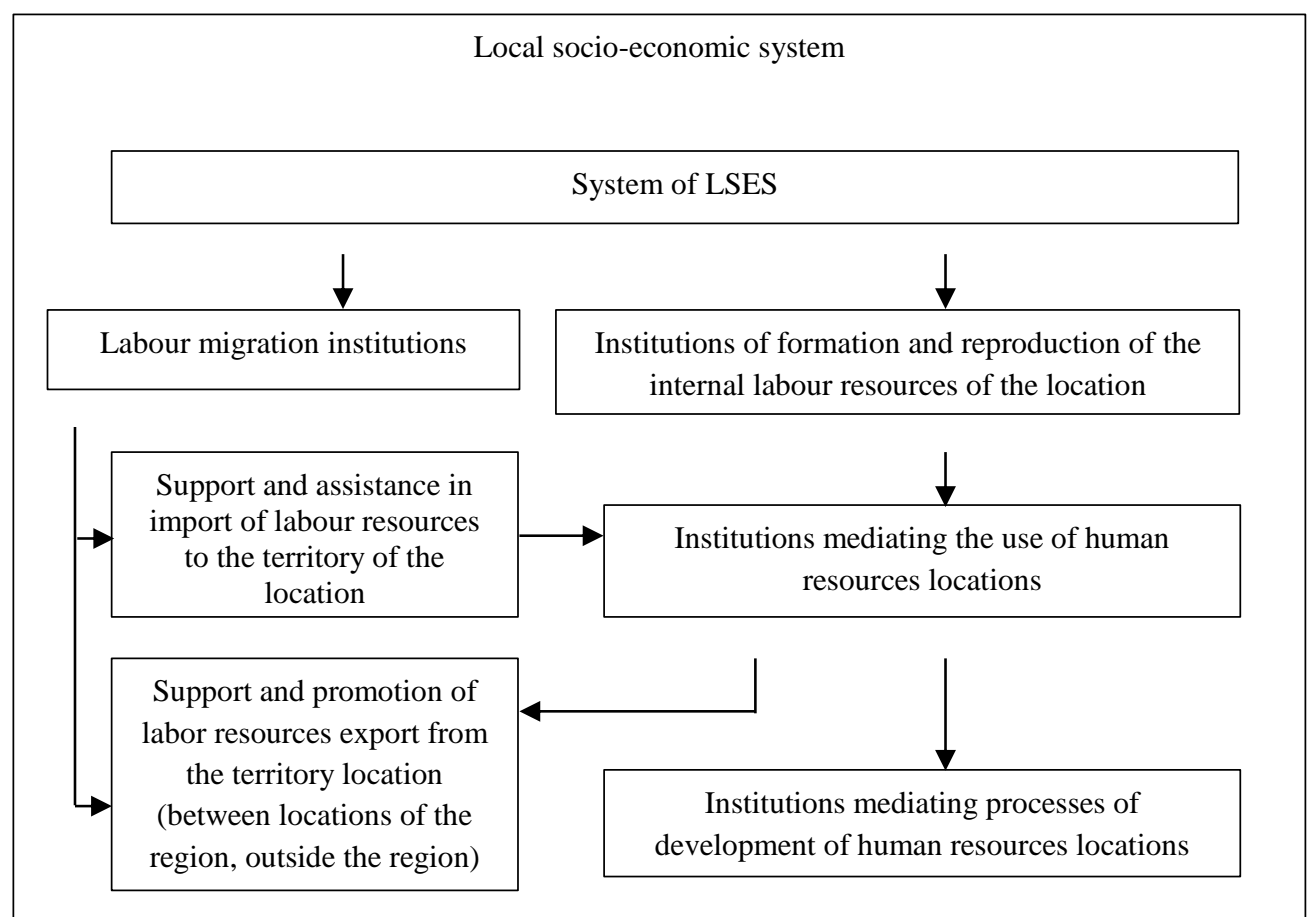

The author's approach represents institutional reserves of efficiency growth of functioning local social and economic systems providing system nature, complexity, continuity and stability of local social and economic processes proceeding in them.

The author's approach in theory and practice of engineering and development of regional socio-economic systems will provide understanding of socio-economic processes at the local and regional level, create conditions for their transparent monitoring, analysis and evaluation, offer adequate managerial approaches that take 
into account territorial specificity of the processes of formation, use, reproduction and development of labor potential as a key function of spatial systems of socio-economic functionality. It is necessary to emphasize actuality and relevance of the implementation now of new methods and approaches to organization of regional and local socio-economic processes in the Krasnodar Region, due to the slowdown in the socio-economic development of the region and its transition to the actual downward dynamics.

The actual gap between declared and implemented goals, tasks and priorities of socioeconomic policy and strategy of the region led to slight recession of the results of the region's economy, which can be further strengthened in conditions of passivity of the managerial system of the region's economy and formal reassurance of positive increases in GRP in actual prices, which do not take into account the inflation factor.

It is necessary to create long-term science-based conception of formation, effective use, reproduction and strategic development of the socio-economic potential, which is impossible without radical revision of regional socio-economic function, considering regional characteristics and advantages. Methods and tools used and planned to be used in practice of strategic management of socio-economic processes in Krasnodar Region require significant clarification and specification in connection with real strategic priorities of regional socio-economic development in the context of the main stages of regional socio-economic process. Otherwise, the Strategy-2030 (as well as the predecessor document, results of which were not even used in the development of the next strategic plan) risks to be formal author's vision, not connected with actual processes relating to the implementation of the regional social and economic function.

In order to form a reliable and representative empirical base that allows to identify and assess dynamics and trends of expectations and perceptions of key socioeconomic transformations in 2016-2018 by the population of the Krasnodar Region we have implemented a comprehensive tracking study that covered all cities and municipal areas of the region and allowed to solve following specific research tasks:

- the general assessment of socio-economic situation in the country and in the region;

- the identification of respondents' attitude to the problem of personal and family / generic unemployment and personal competitiveness;

- the study of the readiness of the population of the region to regional, sub-federal, national and international labor migration;

- indication of price perception and readiness to make large consumer purchases and increase personal credit activity.

The key conclusions of the implemented research development were the following theses: 
- the population of Krasnodar Region in 2016-2018 estimated carried-out and perspective social and economic transformations in general conservatively and with prevalence of pessimistic expectations;

- with rather enough acute perception of continuous growth of consumer prices and stagnation of wages, respondents were very pessimistic throughout the period under consideration about the possibility of large consumer spending or attracting additional credit funds;

- economic situation in their own households, respondents consistently assessed as good, noting the lack of opportunities for further improvement in the current conditions;

- respondents were very susceptible to the situation of employment and unemployment in the regional labour market, while their own experience of dismissal and employment in the period under review was rather positive, as well as aggregated estimates of their own labour competence and competitiveness;

- labour mobility is not one of the competitive advantages of the population of Krasnodar Region, limit for which is intraregional pendulum migration, more amplitude types of such activity were situational throughout the period under review.

\section{Prospects for the Development of Regional Socio-economic Systems}

We believe that one of the promising ideas for development of local and regional socio-economic system of Krasnodar Region is the formation of central agglomeration of Krasnodar - Takhtamukai district of the Republic of Adygea. Modern managed agglomerations can and should become a key factor in the social development of the region provided their whole socio-economic potential is used and importance of maneuvering by human resources on the basis of modern multimodal transport local systems is strenghtened.

In our view the implementation of the project to create an urban agglomeration will lead to forecasted outcomes of development, a set of socio-economic consequences that includes reducing the cost of a square meter of housing by saving on the renovation cost in the existing quarters of residential city housing, reducing the time for daily labor migration within the boundaries of the agglomeration, reducing the utilities cost for life support, growth of population provision quality of the agglomeration with capacities of socio-economic infrastructure, growth of real disposable population income (deducting obligatory expenses and payments on life support) is among basic outcomes, and also economic and ecological effects.

\section{Conclusion}

The implementation of the author's proposal will provide a managed long-term vector of the socio-economic development of the location territory and the region as a whole, will create a real «point of growth» with reasonable and transparent sources of competitive advantages, especially social ones, in the future can become the core of a 
larger agglomeration of interregional and national socio-economic significance. Within functioning such an amalgamation, it will be possible to use the total marketing and logistics potential of the entire territory (Bondarenko et al., 2017).

\section{References:}

Bondarenko, V.A., Erokhina, T.B., Parkhomenko, T.V., Guzenko, N.V. 2017. Marketing and Logistic Instrumentarium of activation of Inter-country Cooperation of Russia and Solving the Issue of Import Substitution. European Research Studies Journal, 1(20), 105-116.

Bondarenko, V.A. 2007. Marketing of Territories: Perspectives of the Financial Attractiveness of Investments in the Territorial Infrastructure. Practical Marketing, 3 (121), 38-44.

Molchan, A. S., Trinca, L.I., Ternovenko, K.O. 2011. Management System of Strategic Priorities of Development of Industrial Potential of the Region. Polythematic Network Electronic Scientific Journal of Kuban State Agrarian University, 65, 212-225.

Molchan, A.S. 2013. Conceptual Aspects of the Theory and Methodology of Formation and Use of the Total Potential of Meso-level Socio-economic Systems. Scientific Bulletin of the Southern Institute of Management, 3, 22-28.

Tinyakova, V.I., Ratushnaya, E.A. 2010. Problems of Substantiation of Investment Decisions: Adequacy, Correctness, Forecast. National Interests: Priorities and Security, 7(64), 73-77.

Volkova, S.A., Tinyakova, V.I. 2013. Modern Facet of Territorial Marketing. Prospects of Science, 4(43), 78-82. 